\section{A escrita como acontecimento discursivo em contexto de formação acadêmica: o dizer circunscrito por leituras}

\begin{abstract}
Writing as a discursive fact in the context of academic training: the saying circumscribed by readings
\end{abstract}

Valnecy Oliveira CORRÊA SANTOS (UFMA) valnecycorrea@hotmail.com

Sulemi FABIANO-CAMPOS (UFRN) sulemifabiano@yahoo.com.br

Recebido em: 22 de jun. de 2018. Aceito em: 05 de abr. de 2019.

\title{
00000000000
}

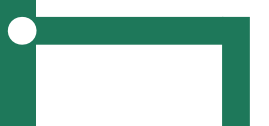

CORREAA SANTOS, Valnecy Oliveir; FABIANO-CAMPOS, Sulemi. A escrita como acontecimento discursivo em contexto de formação acadêmica: o dizer circunscrito por leituras. Entrepalavras, Fortaleza, v. 9, n. 2, p. 315-331, maio-ago/2019.

Resumo: Ao selecionar, como corpus para esta abordagem, textos escritos em contexto de formação acadêmica, concebemos esta análise como um dos exercícios de leitura que têm nos ajudado a compreender as atitudes de leitura na escrita. Neste texto, partimos do pressuposto de que a escrita é um acontecimento discursivo e propomos, ao realizar uma leitura das atitudes de leitura presentes em relatórios de estágio curricular obrigatório em língua portuguesa, no ensino médio, oferecer ao leitor uma compreensão acerca de como as atitudes de leitura corroboram para fortalecer discursos quando se acredita os estar combatendo. Para este exercício de leitura, fundamentamo-nos nos estudos de Bellenger (1979) sobre leitura, na concepção de acontecimento discursivo de Pêcheux (2015) e no princípio da análise relacional, proposto por Apple (1982). Ao concluir a leitura, trazemos como resultado as seguintes percepções: (i) a escrita é acontecimento discursivo circunscrito pela leitura; (ii) a escrita dos relatórios de estágio revela uma leitura que pré-existe a etapa de observação e, por isso, reitera discursos existentes sobre a escola e a prática docente; (iii) a escrita dos relatórios indica que as leituras 
V. $9(2)$

$315-331$ realizadas pelos alunos, futuros professores de língua portuguesa, em processo de formação acadêmica, por ficarem mais restritas às discussões linguístico-textuais e de aplicação, fortalecem discursos sobre a escola e a prática docente, sob a ideologia de os estar combatendo.

Palavras-chave: Leitura e escrita. Formação docente. Relatório de estágio.

Abstract: In selecting, as corpus for this approach, written texts in context of academic training, we conceive this analysis as one of the reading exercises that has helped us to understand reading attitudes in writing. In this text, we start from the assumption that writing is a discursive fact and we propose, when reading the reading attitudes present in reports of curricular traineeship in Portuguese language, in high school, to offer the reader an understanding about how reading attitudes corroborate to strengthen discourses when it is believed that they are being fought. For this reading exercise, we are based on the studies of Bellenger (1979), on the conception of the discursive fact of Pêcheux (2015) and on the principle of relational analysis, proposed by Apple (1982). At the end of the reading, I bring as a result the following perceptions: (i) writing is a discursive fact circumscribed by reading; (ii) the writing of the internship reports reveals a reading that pre-exists the stage of observation and, therefore, reiterates existing discourses about the school and the teaching practice; (iii) the writing of the reports indicates that the readings made by students, future Portuguese language teachers, in the process of academic training, being more restricted to linguistictextual discussions and application, strengthen discourses about school and teaching practice, under the ideology of being fighting them.

Keywords: Reading and writing. Teacher training. Internship report.

\section{Introdução}

Neste texto, apresentamos uma leitura de uma das seções, intitulada Observação em Língua Portuguesa, de um relatório de estágio escrito por aluno de um curso de licenciatura, ao finalizar a primeira etapa do componente Curricular Estágio Supervisionado II - Língua Portuguesa. O trabalho que ora empreendemos procura compreender as atitudes de leitura na escrita.

Partimos do pressuposto dequealeitura apresentadano relatório, por meio do relato de observação da prática docente, não foi realizada pelo aluno/estagiário durante e/ou após o processo de observação. Tratase de uma leitura pré-existente, resultante de sua formação discursiva. O relato pode ser compreendido como um acontecimento discursivo que materializa, na escrita, um discurso de que são os professores que não têm conseguido ensinar Língua Portuguesa aos alunos.

Esse discurso tem se materializado ao longo da história do componente curricular Língua Portuguesa, acompanhando as transformações porque passou o ensino de língua materna, no que se refere à constituição dos objetos de ensino, à metodologia de trabalho e ao processo de formação docente. No âmbito dessas transformações, 
estão as pesquisas realizadas na universidade, objeto de fetichização, segundo Geraldi (2013); as políticas públicas de formação docente; a publicação e a divulgação dos documentos oficiais, dos quais os Parâmetros Curriculares Nacionais de Língua Portuguesa (PCNLP), documento que causou grande impacto na educação básica e popularizou a defesa de que o texto deve ocupar o centro do processo de ensino e aprendizagem, embora isso já tivesse sido anunciado pelas pesquisas acadêmicas, com 0 texto na sala de aula ${ }^{1}$, por exemplo.

Assim, o que propomos, é, ao realizar uma leitura de uma atitude de leitura presente no relatório em análise, oferecer ao leitor uma compreensão acerca de como as atitudes de leitura corroboram para fortalecer discursos, quando se acredita os estar combatendo, ou seja, como a leitura nos escapa, quando acreditamos dominá-la.

Para esse empreendimento, fundamentamo-nos nos conceitos de leitura, propostos por Bellenger (1979); na concepção de acontecimento discursivo, presente em Pêcheux (2015) e no princípio da análise relacional, de Apple (1982). A leitura do relatório de estágio, referenciada por essas lentes teóricas, analisará marcas linguísticas, por meio das quais buscaremos interpretar a atitude de leitura, bem como explicitar a escrita como acontecimento discursivo.

Nessa perspectiva, a leitura favorece o diálogo sobre o processo de formação docente, no que concerne às práticas de observação, leitura e escrita de relatórios de estágio, e permite compreender, por meio da análise das marcas linguísticas, que o sujeito que escreve não é a origem do discurso, embora ocupe o centro do encadeamento discursivo.

\section{Encontro com o corpus, a leitura e o recorte analítico}

Esta leitura busca compreender atitudes de leitura na escrita. O princípio de base para tal empreendimento é o de que tudo parte de um já dito, portanto o sujeito não é a fonte do dizer (PÊCHEUX, 2009). Trata-se de uma leitura embasada pelo pressuposto de que "o texto dos arquivos não é transparente" (PÊCHEUX, 2016, p. 24). Nessa perspectiva, este texto apresenta-se como um exercício de leitura, no qual a escrita acadêmica é compreendida como acontecimento discursivo, "ponto de encontro de uma atualidade e uma memória" (PÊCHEUX, 2015, p. 16), e como parte constitutiva do processo de formação docente.

${ }^{1}$ Obra pioneira sobre o tema, organizada por João Wanderley Geraldi e publicada no início da década de 1990. 
V. 9 (2)

$315-331$

A base da leitura, segundo Pêcheux (2010), encontra-se na relação entre a língua (sistema sintático intrinsecamente passível de jogo) e a discursividade (inscrição de efeitos linguísticos materiais na história). Nesta, a leitura é interpretativa; naquela, é literal. A leitura que propomos consiste em uma análise discursiva de um relatório de estágio, corpus desta abordagem, através da qual esperamos ser possível demonstrar como a escrita revela-se um dizer circunscrito, um acontecimento discursivo.

Acerca do corpus, destacamos que o estágio resultou na escrita de doze relatórios (cada aluno escreveu o seu relatório), textos escritos segundo um padrão e modelo estabelecidos pela universidade em que ocorreu o estágio. Todos os relatórios foram organizados segundo a mesma ordem: introdução; fundamentação teórica; percurso metodológico; resultados e discussões. Essa ordem comporta as seguintes subseções: observação em língua portuguesa e regência em língua portuguesa; projeto interdisciplinar; considerações finais e referências. Cada texto possui, em média, vinte e cinco laudas.

Ao concluir a leitura dos doze relatórios, observamos a existência de um posicionamento muito similar entre os alunos estagiários, ao comentar as etapas de observação e regência em língua portuguesa. Com base nesse dado, selecionamos um relatório ${ }^{2}$ para compor esta análise, que será identificado como R1. O item do relatório selecionado para análise encontra-se na subseção Observação em Língua Portuguesa. Em função da dimensão do texto, alguns trechos foram suprimidos, porém o relato transcrito favorece ao leitor uma visão do processo de observação. Da transcrição, alguns trechos foram selecionados para análise e serão identificados pelo termo 'Passagem', compreendido como o lugar em que algo acontece.

\section{A leitura como prática e local de constituição dos discursos}

Sempre que se usa a palavra, imanente ao uso, há uma atitude de leitura, por ser esta "ponto de partida para a ação" (BELLENGER, 1979, p. 10), fonte da qual emana o dizer, seja por meio da leitura de mundo, seja por meio da leitura da palavra, como ressaltou Freire (1989).

\footnotetext{
${ }^{2}$ Considerando o fato de termos observado a existência de um posicionamento semelhante entre os alunos estagiários ao comentar as etapas de observação e regência em língua portuguesa, a escolha do relatório de R1 não se justifica por aspectos formais presentes no texto, mas, conforme Pêcheux (2015), por ser um exemplar dentro de um conjunto de recorrências que irrompem no espaço da repetição discursiva.
} 
Por serem ponto de partida, as leituras realizadas criam, no leitor, verdades. A leitura torna-se, assim, "instrumento de julgamento" (BELLENGER, 1979, p. 10). Bellenger explica essa definição com exemplos e em um deles cita a passagem vivida pela criança de seis anos para uma espécie de segunda etapa do processo de escolarização, momento em que a escola e a sociedade julgam seu desempenho pelo saber ler, pelo "já está alfabetizado". Esse julgamento, todavia, provém primeiro da inserção disso como verdade numa dada coletividade. A relação do leitor com o texto, dentro desse princípio de construção de verdades, ocorre movida por forças, porque, normalmente, o texto já chega ao leitor com uma imagem pré-construída: o que diz o texto, quem o escreveu, o que essa leitura pode trazer etc.

Outra definição apresentada por Bellenger (1979, p. 10) é leitura como "nervo vivo da informação". Uma metáfora muito interessante uma vez que os nervos, no sentido que o termo adquire quando se fala no corpo humano, são responsáveis pelos impulsos nervosos, por todo o potencial de ação. O vocábulo 'vivo' reitera esse potencial da leitura e o interliga à primeira definição: a leitura como ponto de partida da ação, algo em pleno vigor, em movimento, que impulsiona.

A leitura é apresentada, ainda, como ação que justifica: "Ler é também poder justificar-se ("eu li que, deve-se ter lido...)" (BELLENGER, 1979, p. 12). Nesse ponto, a leitura aproxima-se mais do contexto acadêmico, no qual o dizer tem buscado sempre o sustentáculo no dizer do outro. Ao longo da história, essa prática é reiterada. Ao aluno, cumpre a leitura de um conjunto de obras, através do qual ele deverá construir o seu dizer.

Nesse sentido, o esperado é que a leitura seja a ponte para a construção de um novo dizer a partir da experiência com o dito. Entre esse ideal e o que se tem observado como realidade, por meio de pesquisas acerca da escrita acadêmica ${ }^{3}$, é que o leitor tem dificuldade de desprender-se das palavras do outro e dialogar com ela. Assim, a leitura acaba por direcionar a sua visão e o seu agir e isso reverbera na escrita. Nessa perspectiva, "ler é uma lei de nossa sociedade, é uma postura social" (BELLENGER, 1979, p, 14). A essa afirmação interligamos um comentário feito por Bourdieu, durante um debate com Roger Chartier, acerca das práticas de leitura.

${ }^{3}$ Nesse âmbito, citamos, como exemplo, os trabalhos desenvolvidos pelos membros do Grupo de Estudos e Pesquisa Produção Escrita e Psicanálise (GEPPEP), do Grupo de Pesquisa em Estudos do Texto e do Discurso (GETED) e do Grupo de Pesquisa, Ensino, Leitura e Escrita (GPELE). 
V. 9 (2)

$315-331$

maio-ago

2019

[...] as declarações concernentes ao que as pessoas dizem ler são muito pouco seguras em razão daquilo que chamo de efeito de legitimidade: desde que se pergunta a alguém o que ele lê, ele entende 'o que é que eu leio que mereça ser declarado?' Isto é: 'o que é que eu leio de fato de literatura legítima?' Quando lhe perguntamos 'gosta de música?', ele entende 'gosta de música clássica, confessável?'. E o que ele responde não é o que escuta ou lê verdadeiramente, mas o que lhe parece legítimo naquilo que lhe aconteceu de ter lido ou ouvido. [...] Nessas condições, onde encontrar indicadores dessas leituras diferenciais? (BOURDIEU apud CHARTIER, 2011, p. 236-237).

Na definição de Bellenger e no comentário de Bourdieu, encontramos outro aspecto do processo de escrita como revérbero da leitura, o jogo ideológico acerca da verdade. Ao tomar a palavra escrita, é comum àquele que escreve projetar a imagem de si no outro, o leitor. O que espera que eu diga, quem espera que eu tenha lido. É nesse ponto que a leitura nos escapa, porque o discurso chega e projeta o real da leitura, quando acreditamos dominá-la.

É nesse ponto, ainda, que a leitura torna-se mecanismo de controle. O lido é, ideologicamente, concebido como verdade e, com isso, discursos tornam-se hegemônicos, o poder faz-se invisível ao ser incorporado na própria estrutura de trabalho (APPLE, 2002). Nesse aspecto, a análise relacional de Apple (1982) ajuda-nos a compreender a existência de uma relação intrínseca entre as partes envolvidas num processo de formação, bem como favorece a percepção acerca de como, na relação entre essas partes, um discurso torna-se hegemônico, controla o olhar dos sujeitos em formação e o conduz para um determinado ponto.

A partir dessas concepções teóricas, passamos à leitura do relatório, à análise das passagens, cujas declarações referentes à primeira etapa de estágio, a observação, exemplificam e ajudam a compreender as atitudes da leitura.

\section{O exercício de leitura em busca do discurso}

Tendo delineado uma concepção de leitura, encontramos possibilidades para uma interpretação das passagens escritas por R1 em seu relatório de estágio. Nesta seção, buscamos colocar-nos "em posição de 'entender' a presença de não-ditos no interior do que é dito" (PÊCHEUX, 2015, p. 44). Para isso, a leitura realizada, conforme já anunciado, busca depreender o discurso. Focalizaremos, assim, dois aspectos na análise: (i) identificar marcas linguísticas indicativas de leitura na escrita que corroborem para a compreensão de escrita como 
acontecimento discursivo; (ii) demonstrar, por meio dessas marcas, os modos como a leitura escapa quando o leitor usa a palavra escrita.

Para realizar esse percurso, tomamos o texto presente na seção do relatório escrito por R1, intitulada Observação em Língua Portuguesa. Segue o texto, com pequenos recortes, feitos no intuito de eliminar marcas de identificação e também considerando o espaço deste artigo.

Foram observadas 12h/a de Língua Portuguesa [...]. As observações aconteceram nas aulas de duas professoras de Língua Portuguesa, uma das turmas de $1^{\mathrm{O}}$ ano e outra das turmas de $2^{\circ}$, e ocorreram em três dias X, foram observadas 4h/a em cada dia.

Os próximos parágrafos dessa subseção relatam as experiências de observação em cada uma das turmas supracitadas. No dia X, observei o $1^{\circ}$ e $2^{\circ}$ horário no $1^{\circ}$ ano "A" e o $3^{\circ}$ e $4^{\circ}$ horário no $1^{\circ}$ ano "B". Neste dia o $1^{\circ}$ ano "A" contava com 36 alunos em sala e o $1^{\circ}$ ano "B" somava 32 alunos. Nas duas turmas a professora trabalhou o mesmo conteúdo: "Língua e Linguagem" e a metodologia usada nas salas também foi a mesma. A professora iniciou a aula nas duas turmas falando aos alunos o conteúdo da aula e que ela seria realizada no auditório. Em seguida, ela falou sobre nossa presença na sala e pediu que nos apresentássemos à turma [...]. Após as apresentações acompanhamos a turma ao auditório, local amplo, bem iluminado e com ar-condicionado. No auditório ela abordou o conteúdo por meio de exposições de slides que continham conceitos de língua, linguagem e os tipos de linguagem, além de alguns exemplos de linguagem verbal e não verbal como o "Abaporu" de Tarsila do Amaral, o semáforo e o "Soneto de Fidelidade" de Vinícius de Moraes. Esses exemplos, assim como os demais, foram analisados superficialmente pela professora e pelos alunos. Pela forma como usou o "Soneto de Fidelidade", ela mostrou e confirmou o que dizem autores como Antunes (2003) sobre o uso de textos literários na escola, que esta reduz os textos literários a pretextos e os esvazia de sua função poética, presente, sobretudo na poesia. A docente, em certos momentos, questionava os alunos sobre o conteúdo, mas inicialmente eles não corresponderam, talvez por timidez por causa das estagiárias, uma vez que até a professora demonstrou, inicialmente, certo desconforto. Só depois de alguns minutos eles passaram a interagir e expor situações concretas e a professora a citar situações próprias do cotidiano dela e dos alunos.

[...]

Já no $1^{0}$ "B" o retorno à sala ocorreu no $4^{\circ}$ horário, após o intervalo, os alunos voltaram agitados e assim permaneceram, principalmente pelas condições da sala: espaço forrado, sem ventilador nem ar-condicionado e com grande número de alunos. Ao voltar do intervalo a professora fez a frequência e então pediu para os alunos reduzirem a conversa e abrirem o livro didático e então foi feita a mesma atividade realizada na turma $1^{\circ}$ ano "A". Nessa turma, assim como na outra, foram poucos os que responderam as questões lidas pela professora, apesar de todos estarem com o livro aberto. Terminando a atividade, a professora falou para eles virarem a página do livro e leu e comentou um texto que discorria sobre texto e, após seus comentários, a aula findou-se. ano: "B" e "C". No $2^{\circ}$ ano "B" a aula aconteceu no $1^{\circ}$ e $2^{\circ}$ horário com 35 
V. 9 (2)

$315-331$ maio-ago 2019

43 alunos em sala. Neste dia a professora abordou o conteúdo "Semântica e 44 Pragmática". A professora iniciou com alguns minutos de atraso e então falou 45 aos alunos o conteúdo da aula e em seguida perguntou o que eles sabiam 46 sobre o mesmo. Mas os alunos estavam conversando sobre outros assuntos e 47 deram pouca atenção a ela. A professora então saiu da sala por alguns 48 minutos para instalar o Data show no auditório e os alunos ficaram na sala e 49 continuaram conversando. Quanto ela retornou falou que eles iriam continuar a 50 aula no auditório.

51 No auditório a professora expos, em slides, os conceitos de Semântica e 52 Pragmática e comentou brevemente cada conceito. Restringindo-se depois 53 apenas a Semântica, ela expos e comentou conceitos de Sinonímia, Antonímia, 54 Homonímia (Homógrafas e Homófonas perfeitas), Paronímia, Polissemia, 55 Conotação e Denotação. Os slides foram lidos por um aluno a pedido da 56 professora e ela indagou várias vezes sobre o que estava expondo. Nos slides 57 havia exemplos de palavras e frases que não foram contextualizadas, com 58 exceção de algumas. Havia também dentre os exemplos algumas tirinhas e a 59 professora pediu aos alunos que falassem sobre elas, alguns alunos fizeram o 60 que ela pediu. Nem todos os slides foram analisados, alguns contendo 61 exemplos. A professora apenas lia e outros só exibia. O $2^{\circ}$ horário terminou 62 com a turma ainda no auditório.

63 No $3^{\circ}$ e $4^{\circ}$ horário, a professora foi para a turma $2^{\circ}$ ano "C" que estava 64 com 32 alunos em sala e realizou uma atividade sobre um trecho do romance 65 "O Mulato" de Aluísio Azevedo. A professora havia deixado uma cópia do 66 trecho do romance com um aluno e os demais deveriam fazer suas cópias e 67 realizar a leitura em casa. Depois de perguntar se todos haviam feito a leitura 68 do fragmento e receber as pouquíssimas respostas positivas e perceber que a 69 maioria da turma estava sem texto, ela pediu mais responsabilidade, 70 compromisso e dedicação por parte dessa maioria. Após essa conversa a 71 professora ditou uma atividade sobre o trecho do romance e que deveria ser 72 respondida pelo fragmento do mesmo. Essa atividade ditada consumiu boa

73 parte da aula, tanto que ela terminou praticamente ao mesmo tempo em que 74 findou o $4^{\circ}$ horário. A atividade era para possibilitar a "interpretação do texto", 75 porém as questões buscavam apenas as informações superficiais e totalmente 76 explícitas no romance, como demostra a $6^{\mathrm{a}}$ questão da atividade: "A 77 verdadeira mãe de Raimundo estava: a - Escrava; b - Casada; c - Viva; d 78 Morta". Com esse tipo de atividade a professora confirma as palavras de 79 Jurado \& Rojo (2006) que dizem que os professores apresentam aos alunos 80 apenas fragmentos das obras e que sua preocupação não é com a fruição ou 81 apreciação estética das mesmas. Comprova também que nas atividades de 82 leitura a "interpretação se limita a recuperar os elementos literais e explícitos 83 presentes na superfície do texto." (ANTUNES, 2003, p.28).

$$
\text { [...] }
$$

84 As aulas observadas no $2^{\circ}$ ano "C" aconteceram com 34 alunos em sala e 85 teve início no auditório da escola, onde a professora utilizou o Data show para 86 trabalhar o conteúdo supracitado. Antes de iniciar a exposição do conteúdo ela 87 nos apresentou para a turma dizendo que nós trabalharíamos o conteúdo 88 detalhadamente, pois ela iria fazer apenas uma introdução do mesmo. E então 89 iniciaram as exposições de slides, os mesmos apresentados no $2^{\circ}$ ano "B". 90 Nesta turma, uma aluna ficou responsável por passar os slides e os outros, 91 principalmente os que estavam na frente, liam e participavam da aula. Durante 92 a apresentação de slide a professora permaneceu no palco do auditório.

$$
\text { [...] }
$$

93 Com as observações percebemos que uma de nossas dificuldades 94 durante as regências seriam em relação ao controle e organização da turma, o 95 que às vezes, é motivado pelas condições da sala: forrada, quente, sem ar96 condicionado ou ventilador (Texto escrito por R1). 
A leitura do texto favorece ao leitor construir uma representação do cenário retratado. O texto indicia a relação de proximidade que o observador, R1, tem com o contexto observado. Ele faz menção à divisão de aulas por horários, aos conteúdos utilizados na aula e à metodologia utilizada pela professora.

Pêcheux (2015, p. 16) define um acontecimento como o "ponto de encontro de uma atualidade e uma memória". Com base nessa proposição, trazendo-a para este estudo, compreendemos a etapa de observação e a etapa de escrita do relatório como dois acontecimentos interligados, porém distintos. A etapa de observação representa, para nós, um pressuposto de que os estagiários tenham ido à escola realizá-la. Já a segunda etapa, a escrita do relatório, por seu caráter material conferido pela escrita, adquire concretude, passando a ser o acontecimento discursivo, foco desta análise.

Essa concretude conferida pela materialidade da escrita, todavia, não retrata, fielmente, o primeiro acontecimento, a etapa de observação, pois a escrita reconstrói o real, a partir do olhar de um observador, sujeito ideologicamente constituído, que usa a palavra para dizer "eu" e, por meio dela, externa uma atitude de leitura. Trata-se de uma relação em que esse "eu", sujeito marcado pela enunciação, é ser real e é sujeito de discurso, ou seja, é uma forma-sujeito (PÊCHEUX, 2009).

A primeira passagem que analisaremos encontra-se nas linhas 7-29. Nela, há termos e expressões semanticamente interligados ao universo pedagógico no que se refere à organização escolar: horário, $1^{0}$ ano "A", "B", sala, alunos, turmas, professora; ao conteúdo de ensino: língua, linguagem, tipos de linguagem, linguagem verbal e não verbal; e à metodologia: trabalhou, metodologia, iniciou a aula, abordou o conteúdo, exposições de slides; exemplos; foram analisados etc. Todos esses termos, considerando a escrita do relatório de estágio como acontecimento, ajudam a reconstruir o acontecimento primeiro: a observação em sala de aula numa situação de estágio. Numa análise discursiva, esses são termos que se mantêm no espaço da "manipulação de significações estabilizadas" (PÊCHEUX, 2015, p. 51), ou seja, daquilo que é esperado para um dado espaço discursivo. Essa estabilidade é, contudo, alterada quando R1 sai do plano do registro de observação, entra no plano do comentário e escreve:

Esses exemplos, assim como os demais, foram analisados superficialmente pela professora e pelos alunos. Pela forma 
V. 9 (2)

$315-331$

como usou o "Soneto de Fidelidade", ela mostrou e confirmou o que dizem autores como Antunes (2003) sobre o uso de textos literários na escola, que esta reduz os textos literários a pretextos e os esvazia de sua função poética, presente, sobretudo na poesia (Passagem escrita por R1, linhas 19-24, grifo nosso).

Nessa passagem, o acontecimento sai do plano das significações estabilizadas e entra no das "transformações de sentido" (PÊCHEUX, 2015, p. 51), como se o enunciado fosse deslocado. R1 pausa a descrição da aula e faz um comentário sobre o uso dos textos utilizados como exemplos: foram analisados superficialmente pela professora e pelos alunos (linha 19-20). A atitude de leitura de R1 é marcada pelo emprego do modalizador superficialmente, pois, através dele é emitido um juízo de valor sobre a forma como os textos foram e como R1 acredita que deveriam ser analisados.

R1 não explicita sua compreensão acerca do que seria uma análise e porque a considera superficial. Essa ação da escrita, manifesta por meio desse lugar vazio, indicia um registro do discurso-outro, "presença virtual na materialidade descritível da sequência [...] princípio do real sócio-histórico" (PÊCHEUX, 2015, p. 54). A atitude de leitura de R1 indica a existência de uma concepção acerca de como deve ser realizada uma análise textual. Desse ponto de vista, é possível deduzir que a expressão utilizada por R1 - analisados superficialmente - é fruto de sua memória discursiva, das leituras realizadas sobre o trabalho com o texto no processo de ensino e aprendizagem de língua portuguesa.

Em seguida, R1 focaliza um dos textos - "Soneto de Fidelidade" - e tece outro comentário. Novamente, desestabiliza a ordem do dizer e cria outra cena, pois seu foco de atenção muda para o uso do texto literário: ela mostrou e confirmou o que dizem autores como Antunes (2003) sobre o uso de textos literários na escola (linhas 21-22). Nesse comentário, a atitude de leitura é observada por meio do uso dos verbos - mostrou, confirmou - e pela referência aos autores, mais especificamente, a Antunes (2003), pois denota tomada de posição e efeito de identificação no discurso-outro, adquirindo valor de argumento para o comentário de R1. Nas linhas 73-76, essa relação discursiva torna-se mais nítida quando R1 volta a utilizar uma expressão com sentido similar, ao escrever: 
A atividade era para possibilitar a "interpretação do texto", porém as questões buscavam apenas as informações superficiais e totalmente explícitas no romance, como demostra a $6^{\mathrm{a}}$ questão da atividade: "A verdadeira mãe de Raimundo estava: a - Escrava; b - Casada; c - Viva; d - Morta" (Passagem escrita por R1, linhas 74-78, grifo nosso).

A presença do discurso-outro é explicitada, ao resgatar a expressão utilizada por R1, nas linhas 81-83, por meio da citação direta de Antunes: nas atividades de leitura a "interpretação se limita a recuperar os elementos literais e explícitos presentes na superfície do texto" (ANTUNES, 2003, p. 28).

É possível observar, ainda, a atitude de leitura na escrita de R1 por meio da relação entre os pronomes ela e esta e o termo escola, presentes na passagem:

[...] ela mostrou e confirmou o que dizem autores como Antunes (2003) sobre o uso de textos literários na escola, que esta reduz os textos literários a pretextos e os esvazia de sua função poética, presente, sobretudo na poesia (Passagem escrita por R1, linhas 21-24, grifo nosso).

Após definir a análise dos exemplos como superficial (linhas 19-20), R1 faz uma retomada no texto, utilizando o pronome pessoal Ela (linha 21). Considerando o princípio da coesão referencial, esse ela refere-se à professora. Ela (a professora) utilizou os exemplos na aula. Segundo o relato de R1, a professora e os alunos analisaram superficialmente os exemplos, mas somente a professora é apontada, por R1, como agente dos verbos mostrou e confirmou (linha 21). É possível, novamente, inscrever o discurso de R1 no discurso-outro, por meio do discurso relatado, pois, ao iniciar o comentário, R1 escreve: ela mostrou e confirmou o que dizem autores como Antunes (2003). A voz de R1 funde-se, pelo discurso, com outras vozes, como a de Antunes (2003), marcada no texto. Ocorre o mesmo fato nas linhas 78-79: a professora confirma as palavras de Jurado \& Rojo (2006); na linha 81, por meio do verbo comprova; na linha 83, pela referência a Antunes (2003). Em todas essas passagens, há as atitudes de leitura na escrita, por meio da tomada de posição e do efeito de identificação. 
V. 9 (2)

$315-331$

$\mathrm{Na}$ relação de sentido construída entre o pronome ela (a professora), o termo escola e o pronome esta (linha 22) há uma espécie de jogo metadiscursivo que modaliza o dizer, por meio do emprego de uma metonímia em que o todo é tomado pela parte. A professora (ela) mostra e confirma um dado, mas éa escola que éapresentada como agente da ação: esta (a escola) reduz e esvazia os textos. É sabido que não é a escola, é o professor quem utiliza os textos. Por relação de contiguidade, a professora é apontada, também, como agente dos verbos reduz e esvazia. Com isso, observamos, no real da língua 4 , o lugar das filiações identificadoras (PÊCHEUX, 2015, p. 53), que reiteram, pelo discurso, os equívocos e problemas no ensino de língua portuguesa como responsabilidades do professor e de suas práticas, pois ele não "trabalha" adequadamente o texto.

Para fechar esta etapa da leitura, embora existam diversos outros pontos que poderiam ser focalizados, há um enunciado que rompe, com mais força, a estabilidade do texto, "registo do ordinário do sentido" (PÊCHEUX, 2015, p. 52). R1, ao longo de seu relato, vem descrevendo as ações desenvolvidas durante as aulas observadas e tece alguns comentários. Essas duas posturas são marcadas no texto, todavia, nas linhas 88-91, essa ordem se rompe, pois um novo fato é relatado e o comentário feito por R1 não é marcado no texto. Segue a passagem:

Nesta turma, uma aluna ficou responsável por passar os slides e os outros, principalmente os que estavam na frente, liam e participavam da aula. Durante a apresentação de slide, a professora permaneceu no palco do auditório (Passagem escrita por R1, linhas 90-92, grifo nosso).

Ao longo do relato, a professora aparece como regente do processo e os alunos são apresentados como passivos às aulas, dispersos, sem cumprir atividades, embora com o livro aberto. A professora sai da regência, uma aluna passa os slides e os alunos leem e participam da aula. R1 não tece comentários acerca da participação dos alunos, como liam ou participavam, mas a ação da professora é destacada, no último enunciado, como estática - ela permaneceu -, porém o lugar - no palco do auditório - indica ou mantém a ideia de distância da ação, a professora passa de protagonista a espectadora, no momento em que a aula ocorreu, no momento em que os alunos liam e participavam da aula.

${ }^{4}$ Ao utilizar a expressão "o real da língua", utilizo como referência Pêcheux (2015). Este, ao utilizá-la, faz menção a Milner, autor de O amor da língua (1978). 
Os dados analisados revelam a leitura como ponto de partida para ação (BELLENGER, 1979), pois R1 demonstra, pela escrita, já possuir o conhecimento acerca do ambiente observado. Esse conhecimento, por expressar-se por meio de termos próprios de um espaço, a escola e seu funcionamento, e de um campo, o ensino de língua portuguesa, foi adquirido, provavelmente, pelas vivências pessoais e pelas leituras realizadas ao longo do processo de formação acadêmica.

Os dados revelam a leitura como instrumento de julgamento (BELLENGER, 1979). R1 não tece comentários acerca da escolha dos conteúdos abordados pela professora, tampouco acerca da metodologia utilizada (por exemplo, a projeção em slides), do comportamento dos alunos, mas os tece em relação ao uso do texto no processo de ensino e aprendizagem de Língua Portuguesa, possivelmente por ser uma das temáticas mais correntes, nas discussões acerca do ensino de Língua Portuguesa, desde a publicação dos PCNLP. Ao fazer isso, mostra as leituras que toma como parâmetro, reitera discursos.

Para tecer seu comentário, R1 cita Antunes (2003), Jurado e Rojo (2006), colocando-os como autores que dialogam sobre a temática. Revela, assim, a leitura como "nervo vivo da informação", como instrumento de justificativa para o dizer e como um poder (BELLENGER, 1979). É como se o sujeito do discurso presente em R1 dissesse: "posso fazer tal análise, porque há nela verdade. Há autores que dizem isso". A atitude de escrita de R1 revela a leitura como uma postura social (BELLENGER, 1979). R1 é aluno, sujeito ideologicamente constituído, que na condição de estagiário, vai a campo de pesquisa e leva, consigo, suas leituras e as marca na escrita.

A escrita do relatório é, assim, um acontecimento discursivo, cujas bases são tecidas antes do acontecimento primeiro - a etapa de observação. Nessa perspectiva, encontramos relação entre a atitude de leitura de R1 e o que diz Pêcheux (2015, p. 29): "Não descobrimos, pois, o real: a gente se depara com ele, dá de encontro com ele, o encontra". R1 registra, no relatório de estágio, a leitura que corrobora para fortalecer discursos, quando acredita os estar combatendo, ou seja, R1 não descobre o real e o registra, depara-se com ele, algo que já existia em sua memória discursiva. A aula, os conteúdos abordados, a postura da professora, o comportamento dos alunos já eram, de certa forma, conhecidos por R1 antes do acontecimento. Nesse ponto, a leitura escapa, quando R1 acredita dominá-la. 
V. 9 (2)

$315-331$

\section{A leitura do discurso}

Após a leitura dos relatórios, aqui representado por R1, é importante um aparte sobre o discurso neles observado, sobre as atitudes de leitura. Para essa abordagem, os fundamentos utilizados estão inseridos no princípio de análise que Apple (1982) denomina análise relacional.

Apple (2002) defende a tese de que, ao tratar das questões referentes à educação, é necessário estabelecer relações entre as partes que compõem um dado processo. Para tanto, apresenta o conceito de análise relacional, que consiste em uma ação de leitura na qual se observa uma atividade social vinculada ao programa mais amplo de instituições que a distribuem.

Nesta abordagem, fazem parte da análise relacional: a situação que mobilizou a escrita, o cumprimento do componente curricular Estágio Supervisionado II, parte I - Língua Portuguesa; o "eu" que observa e escreve o relatório - sujeito representado por R1; o espaço observado; e o registro, ou seja, o que foi observado. Da relação entre essas partes, é possível projetar uma compreensão mais adequada acerca do acontecimento, o estágio curricular.

Em relação a R1, eu que escreve o relatório, trata-se de um aluno de curso de graduação, já nas etapas finais do curso. Um sujeito que vai à escola, campo de estágio, com a atribuição de observar o cotidiano escolar (foram dedicadas 7h/aula para observação do cotidiano escolar) e a prática docente (12h/aula da carga horária total do estágio foram destinadas à observação em sala de aula) para, em seguida, planejar e ministrar aulas de língua portuguesa para alunos do ensino médio.

R1, ao escrever seu relato de observação, descreve a escola campo de estágio, apresentando a localização, o espaço físico, o número de funcionários e de alunos, os materiais disponíveis.

O X dispõe de livros didáticos, Datashow e outros recursos didáticos que auxiliam professores e alunos no processo de ensino-aprendizagem. Porém suas salas são quentes, é quase impossível a realização das aulas após o intervalo, principalmente, em dias que a temperatura está elevada, pois as salas são forradas e não possuem ar-condicionado, com exceção de uma sala que é climatizada, e os ventiladores nas salas não funcionam. Somado a esse fato está a grande quantidade de alunos nas salas, cerca de 40 alunos por turma. 
Essa descrição é reiterada no relatório de observação das aulas em duas passagens (linhas 32-33 e 95-96), mas em nenhum momento essa condição é abordada, sob a forma de comentário, numa relação com o processo de ensino e aprendizagem.

O segundo espaço observado e descrito por R1 é a aula propriamente dita. Em todo o seu relato, R1 descreve as ações docentes numa perspectiva da ação: fez isto, depois isso e depois aquilo. Descreve a ação dos alunos, mas não relaciona, não dialoga, por exemplo, sobre o comportamento dos alunos ou da professora em sala de aula. Os comentários feitos foram relacionados a um único item, o uso do texto, neste caso, com enfoque voltado para o texto literário, mostrando, bem nitidamente, as influências das leituras e das discussões que se tem feito sobre esse tema.

Essa ausência de comentários, ou seja, aquilo que não é dito no texto pode ser um indício da presença hegemônica de um tema em detrimento dos demais. O relato mostra uma projeção similar à de um espelho, no qual "a imagem pode estar distorcida por imperfeições do vidro, mas de forma geral aquilo que se vê corresponde ao objeto que se tem" (APPLE, 2002, p. 83). O uso do texto da sala de aula, no processo de ensino e aprendizagem de língua portuguesa, tem ocupado um espaço de destaque nos currículos dos cursos de graduação, nas discussões sobre o ensino de língua. Afunilando um pouco mais, desde a publicação dos PCNLP, o uso do texto tem sido o ponto, como se todas as demais questões que envolvem a processo de ensino e aprendizagem, mais especificamente, o ensino de Língua Portuguesa na escola fossem apagadas. R1 apresenta, no relato, muitos pontos que poderiam ter sido trazidos para os âmbitos do comentário: o uso do livro didático, os conteúdos trabalhados pela professora, a questão posta aos alunos, mas não o fez, possivelmente porque um discurso já se fez hegemônico, o de que o texto ocupa o centro do ensino de língua materna, como foi possível observar na escrita do relato.

Diante do exposto, a leitura feita dos doze relatórios, mas exposta aqui por meio de um exemplo somente, mostra-nos que é necessário possibilitar, aos alunos da graduação, um alcance global às questões e objetos de ensino, buscando evitar que um torne-se hegemônico. É fato que o texto é a unidade de ensino de língua, mas se faz necessário compreender os fenômenos que o envolvem nos mais diversos aspectos, como os linguísticos em suas diversas subdivisões; os semânticos, os formais; os pragmáticos entre outros. 
V. 9 (2)

$315-331$

\section{Considerações finais}

Nenhuma leitura crítica pode dispensar uma apropriação objetiva prévia, verificável pela capacidade de reformulação (BELLENGER, 1979).

Ao final desta leitura, trazemos como resultado algumas percepções, as quais buscaremos desenvolver nos parágrafos que seguem, no intuito de chegar ao proposto no início do artigo: demonstrar como a escrita revela-se um dizer circunscrito, revérbero da leitura, um acontecimento discursivo.

No início, esta leitura trouxe como pressuposto que a leitura de R1, acerca da observação da prática docente, não fora realizada durante e/ou após o processo de observação, e sim o resultado de uma leitura pré-existente. A análise possibilitou confirmar esse dado por meio do discurso, da rede de filiações de sentido que foi, pouco a pouco, se reconstruindo com a leitura do texto. Na escrita do relato, R1 revela o discurso-outro, fruto de sua memória discursiva. Assim, assume posições, reitera discursos, fazendo da escrita um acontecimento discursivo circunscrito pela leitura.

Como segunda percepção, reiteramos a escrita dos relatórios de estágio como leitura que pré-existe à etapa de observação e que, por isso, reitera discursos já postos sobre a escola e a prática docente. Essa percepção foi possível pela leitura do relato, no qual a prática docente foi colocada em destaque tanto nas descrições, quanto nos comentários, a ponto de receber um destaque maior no penúltimo parágrafo do relato quando a aula acontece enquanto a professora permanece no palco do auditório.

O relato de R1 demonstra que o discurso acerca do texto como objeto de ensino e aprendizagem de língua já está posto. Esse discurso indicia que as leituras realizadas pelos alunos, futuros professores de língua portuguesa, têm ficado mais restritas às discussões linguístico-textuais e de aplicação. Ao focar prioritariamente nesse ponto, fortalecem discursos sobre a escola e a prática docente, sob a ideologia de os estar combatendo.

Concluímos esta abordagem resgatando a epígrafe posta no início das considerações finais, no sentido de situar a leitura que ora apresentamos como a busca pelo exercício da leitura crítica, em que primeiro é necessário apropriar-se das materialidades linguísticas para, em seguida, por meio da interpretação, reformular o dito, buscando colocar-se à escuta dos ecos do discurso. 
Frente ao exposto, observamos a relevância de, após a etapa de escrita de relatórios de estágio, haver leitura e análise com os alunos público-alvo do processo, para que eles possam refletir sobre os conceitos e discursos, por eles, assumidos.

\section{Referências}

ANTUNES, Irandé. Aula de português: encontro e interação. São Paulo: Parábola Editorial, 2003.

APPLE, Michael W. Ideologia e Currículo. São Paulo: Brasiliense, 1982.

Educação e poder. Porto Alegre: Artes Médicas, 2002.

BELLENGER, Lionel. Os métodos de Leitura. Rio de Janeiro: Zahar Editores, 1979.

BOURDIEU, Pierre. A leitura: uma prática cultural. In: CHARTIER, Roger (Org.). Práticas de leitura. 5. ed. São Paulo: Estação Liberdade, 2011, p. 231-253.

FREIRE, Paulo. A importância do ato de ler: em três artigos que se completam. 23. ed. São Paulo: Cortez, 1989.

GERALDI, João Wanderley (Org.). o texto na sala de aula. 3. ed. São Paulo: Ática, 2005.

J. W. Portos de passagem. 5. ed. São Paulo: Martins Fontes, 2013.

JURADO, Shirley; ROJO, Roxane. A leitura no ensino médio: o que dizem os documentos oficiais e o que se faz? In: BUNZEN, Clécio; MENDONÇA, Márcia (Org.). Português no ensino médio e formação do professor. São Paulo: Parábola Editorial, 2006, p. 37-56.

MILNER, Jean-Claude. 0 amor da língua. Porto Alegre: Artes Médicas, 1987.

PÊCHEUX, Michel. Semântica e discurso. 4. ed. Campinas, SP: Editora da Unicamp, 2009.

Ler o arquivo hoje. In: ORLANDI, Eni P. (org.). Gestos de leitura: da história no discurso. 3. ed. Campinas, SP: Editora da Unicamp, 2010, p. 49-59. Pontes, 2015.

O discurso: estrutura ou acontecimento. 7. ed. Campinas, SP:

Abertura do Colóquio. In: CONEIN, Bernard; COURTINE, JeanJacques; GADET, Françoise, et. al. (Org.). Materialidades discursivas. Campinas, SP: Editora da Unicamp, 2016, p. 23-29. 